\title{
Questioning the Stereotype of the "Malingering Bureaucrat": Absence from Work in the Public and Private Sector in Germany
}

\author{
Stephanie Prümer and Claus Schnabel*
}

\section{INTRODUCTION}

The public sector differs from the private sector in many respects, most notably its higher employment security, the virtual absence of market competition, and the stronger roles of unions and worker participation. What is also often said to be typical for the public sector is its relatively high level of absence from work. In the US, for instance, the ratio of workers with absences due to illness or injury to total fulltime employment was 1.8 percent in the private sector in 2017, whereas this absence rate amounted to 2.4 percent in the public sector and was particularly high in federal government (Bureau of Labor Statistics 2018). In Germany, the popular magazine FOCUS Online (2017) recently put up the question why certain civil servants report to be sick twice as often as other employees. In the UK, the annual sickness absence benchmarking survey by XpertHR showed for the year 2015 that "absence rates in the public sector continued to be higher than the private sector" (Faragher 2016), and Chancellor George Osborne announced a review of sickness absence and sick pay in the public sector (Bevan 2016). ${ }^{1}$ Although such statements are typically based on purely descriptive empirical evidence and pundits quickly point out that the public and the private sector also differ in many other sickness-relevant aspects such as plant size, occupations, and workforce composition, the stereotype of the "malingering bureaucrat" has become firmly established (Bevan 2016, Oppolzer 1999).

* Stephanie Prümer and Prof. Dr. Claus Schnabel, both Friedrich-Alexander-University of ErlangenNürnberg, Lange Gasse 20, 90403 Nürnberg, Germany. E-Mail: stephanie.pruemer@ fau.de and claus. schnabel@fau.de. For helpful comments and suggestions, we would like to thank Laszlo Goerke, Tina Hinz, and Daniel Lechmann as well as the editors and two reviewers of this journal. Open access funding enabled and organized by Projekt DEAL. [Correction added on 21 October 2020, after first online publication: Projekt DEAL funding statement has been added.]

${ }^{1}$ Government reactions in response to absence rates of public sector employees that are said to be higher than in the private sector are also found in other countries such as Italy (De Paola et al. 2014), France (Barreix 2012) and Canada (McGrandle and Ohemeng 2017). D'Amuri (2017) provides a rough descriptive comparison of sickness absence in various (groups of) countries suggesting that its incidence is higher among public sector employees. 
Absence from work is costly to enterprises and society as it is associated with continued wage payments to absent employees, an underutilisation of labour, corresponding productivity losses and reductions in customer satisfaction, increased administrative costs, employee replacement cost, and reductions in workforce morale due to heavier workloads. ${ }^{2}$ Concerning the public sector, where governments in many countries try to reduce spending and improve efficiency, it is often stressed that the seemingly excessive absence rates of employees result in additional costs to taxpayers and in adverse effects on the quality of public services (De Paola et al. 2014, McGrandle and Ohemeng 2017). ${ }^{3}$

Because of the substantial consequences of absenteeism in all sectors, quite a few studies have tried to quantify the extent of worker absence (see, e.g., the international evidence reported by Barmby et al. 2002, Lusinyan and Bonato 2007, Livanos and Zangelidis 2013). Several strands of the literature have provided explanations and theoretical analyses of work absence and its determinants from various perspectives (McGrandle and Ohemeng 2017 provide a brief classification of approaches). Economists have analysed absenteeism either within the framework of the static neoclassical labour supply model as the result of an individual's labour-leisure choice, or they have made use of efficiency wage and contractual models (see Brown and Sessions 1996 or Treble and Barmby 2011 for reviews of this literature). These approaches, however, tend to ignore employees' state of health that is the centre of the medical statistics literature. In addition, occupational health researchers, sociologists and psychologists stress the importance of working conditions, work climate, job satisfaction, and motivation (see Beemsterboer et al. 2009). The various perspectives taken result in a long list of potential determinants of sick leave and absence from work.

These determinants have been investigated in a substantial number of empirical studies conducted by economists, sociologists, psychologists, and occupational health researchers (for reviews, see, e.g., Thalmaier 2002, Allebeck and Mastekaasa 2004, Osterkamp and Röhn 2007, Beemsterboer et al. 2009). Most of these analyses focus on paid employees in the private sector, and some of them also take account of self-employed individuals (e.g., Spierdijk et al. 2009, Lechmann and Schnabel 2014). Compared to this bulk of studies, empirical research with a special focus on absence from work in the public sector or with explicit comparisons between the public and private sector is relatively rare.

That said, there exist some studies that investigate absence from work across all sectors of the economy and typically include a dummy variable for the public sector. The estimated coefficient of this dummy variable has been found to be

\footnotetext{
${ }^{2}$ That said, staying home may also be sensible if showing up for work when being sick is associated with lower productivity and the risk of infecting co-workers.

${ }^{3}$ The quality of public services may in turn affect economic growth, as argued by Oto-Peralias and RomeroÁvila (2013). They show that when the quality of public administration is high, the magnitude of government spending does not appear to be growth-inhibiting.
} 
insignificant in some studies (see, e.g., Böckerman and Ilmakunnas 2008 for Finland) but positive and statistically significant in others (see, e.g. Blázquez Cuesta 2012 for Spain). In their analysis of 14 EU countries, Frick and Malo (2008) report that the number of absence days per year is about 1.4 higher for public sector than private sector employees, ceteris paribus. ${ }^{4}$ The empirical evidence is also mixed for Germany: In some studies, the public sector dummy points to higher sickness absence in this sector (see, e.g., Pfeifer 2013). A recent analysis with GSOEP data by Arnold et al. (2018) reports sickness incidence to be 11.6 percent higher and sickness days to be about 1.5 days higher in the public sector, ceteris paribus. In contrast, other studies find increased absenteeism in the public sector only for certain groups of workers such as men or white-collar employees (Thalmaier 2002, Störmer and Fahr 2013). Unfortunately, these studies do not specifically investigate whether the determinants of absence differ between employees in the private and public sector, whether differences in workloads and job satisfaction between both sectors play a role, and whether employees in the public sector react differently to problems of health and working conditions.

Such a comparison should be worthwhile because the incentive structure regarding (sickness) absence somewhat differs between private and public sector employees and even between different groups of employees in the public sector. In Germany, all employees receive $100 \%$ sick pay from the first day of absence and in principle they do not need a doctor's certificate of incapacity for work if their sickness does not last more than three days. However, employers are free to demand such a certificate already on the first day of sickness, and there is anecdotal evidence that employers in the private sector more often make use of this possibility. Long periods of work absence are in principle a legally accepted cause for dismissal both in the private and public sector. Employment protection, however, is in fact much higher in the public sector. This applies to contractional public sector employees, whose employment protection increases with tenure and age, and even more for the group of civil servants that is virtually "undismissable" (Riphahn 2004: 353). These differences in incentives might result in higher absence from work of public sector employees. ${ }^{5}$

Against this backdrop, this paper contributes to the literature in three ways: First, using a large and representative data set for Germany, we calculate and compare the incidence and extent of absence from work by individuals in the public and the private sector, finding substantial differences between both

\footnotetext{
${ }^{4}$ See also the econometric study by Arnold and de Pinto (2015) for 34 European countries that uses a private sector dummy and finds that sickness absence is about 0.9 days lower for employees in the private sector. ${ }^{5}$ Focusing on the behavioural effects of probation periods, Riphahn and Thalmaier (2001) look at employees in the private and public sector and find that for public sector employees the predicted probability of a work absence is significantly increased after the probation period is completed. Riphahn (2004) shows that among public sector employees those with higher employment protection record more days of absence.
} 
groups. Second, based on the theoretical and empirical literature from various disciplines, we analyse the determinants of work absence in the public sector and examine how they differ from those of employees in the private sector. Third, we discuss whether opportunistic behaviour (i.e. potential shirking and moral hazard problems) plays a bigger role in the public sector and whether the stereotype of the "malingering bureaucrat" is more than a catchphrase in the tabloid press.

The outline of the paper is as follows: Section II provides a brief survey of the theoretical and empirical literature on absenteeism and discusses whether its insights equally apply to employees in the public and private sector. In section III, we present our dataset and some descriptive evidence. Section IV displays the results of our econometric study, analysing the probability of ever having been absent as well as the number of days of absence conditional on ever having been absent both for private and public sector employees. Section V provides some concluding remarks.

\section{THEORETICAL CONSIDERATIONS AND EMPIRICAL LITERATURE}

Absence from work (also called absenteeism) is a pervasive and complex phenomenon that may be regarded as a "wicked problem" (McGrandle and Ohemeng 2017). In the most general sense, it can be defined as "the failure to report for work as scheduled" (Johns 2009: 7). Theoretically, one may crudely distinguish between involuntary absence from work due to "genuine" sickness and voluntary absence reflecting opportunistic behaviour by workers, but in practice there are massive methodological problems of discriminating between voluntary and involuntary absence. Therefore, in this paper we take absenteeism to include all kinds of absence from work on workdays for whatever reason, be it sickness, withdrawal from the workplace or actively trying to reach a better labour-leisure time allocation. We thus acknowledge the substantial evidence that "sickness absence is not purely a response to a medical condition" (Barmby et al. 2002: F315) and the fact that even a doctor's certificate merely reflects this doctor's subjective assessment of the patient's health situation and her fitness for work. In the following, we will classify the vast theoretical and empirical literature on the determinants of absence from work according to those factors (or group of variables) it mainly focuses on, ranging from health and working conditions over labour supply considerations and working hours to job and income (dis)satisfaction and employment protection. This approach (also taken by other researchers like Leigh 1991, Beemsterboer et al. 2009 and Lechmann and Schnabel 2014) enables us to discuss whether the insights of the respective literature are equally relevant for individuals in public and private sector employment and to test this conjecture with our data. 
A prime determinant of (sickness) absence strongly emphasized in the medical statistics literature is individuals' state of health. Relatedly, occupational health researchers stress the importance of unhealthy working conditions, physical and mental workload, and other work circumstances. Adverse working conditions, which make absence from work more likely by increasing employees' disutility from work, also play a role in standard economic models (such as Allen 1981). Consequently, many empirical studies report that the frequency and duration of (sickness) absence is significantly related to health and work characteristics such as health complaints, perceived workload, working conditions, and work strain (see, e.g., Leigh 1991, Arnold and de Pinto 2015, the survey by Beemsterboer et al. 2009, and the meta-analysis by Darr and Johns 2008; Beblo and Ortlieb 2012 and Störmer and Fahr 2013 provide evidence on Germany). It is sometimes argued that health issues play a more important role for explaining sickness absence in the public than in the private sector in Germany since the public sector is a more socially-minded employer and less selective in hiring or keeping contractual employees with respect to their (age-related) health status and capabilities (see, e.g., Oppolzer 1999).

Another potential determinant of absenteeism that is mainly stressed by economists is employees' working time. In this view based on the standard neoclassical labour supply model (see Allen 1981), absence from work is interpreted as an employees' strategy to bring actual hours worked in line with desired hours if the working hours laid down in the work contract are higher than his desired hours. Employees will thus be absent whenever the benefits of missing work are greater than its costs, and they are more likely to be absent, the higher sickness benefits and the less flexible work schedules are (a review of this strand of literature is provided by Brown and Sessions 1996). Several empirical studies show that working hours and working time arrangements do play a role in explaining absenteeism, although not all empirical results are in accordance with theoretical expectations (see, e.g. Dionne and Dostie 2007, Lusinyan and Bonato 2007, as well as Thalmaier 2002 and Lechmann and Schnabel 2014 for Germany).

Job dissatisfaction is a further motive for being absent from work that has been emphasized for a long time by applied psychologists (see, e.g., Steers and Rhodes 1978). This subjective measure of well-being may reflect a wide range of unsatisfying factors at the workplace such as low psychological control over the work situation, frustrating experiences at work, unpleasant working conditions, deficits in employer-employee communication, and income dissatisfaction. From an economic perspective, higher absenteeism (say, in the public sector) could also be interpreted as a compensating differential if employees (in this sector) are less satisfied with their income and thus take off more sick time to compensate for this deficit. In a substantial number of empirical studies, job (dis)satisfaction has been found to affect absenteeism of employees (see the surveys by Allebeck and Mastekaasa 2004 and by Beemsterboer et al. 2009). For 
Germany, however, the analysis by Störmer and Fahr (2013) does not show statistically significant effects of work and income satisfaction on work attendance. ${ }^{6}$

In an economic perspective, (voluntary) absence from work may also depend on factors like principal-agent problems, moral hazard and shirking. The moral hazard of 100 percent sick pay paid by the employer and asymmetric information between employees and their employer regarding individuals' actual health may induce employees to claim sick pay despite being in good health, thus increasing absence rates. Shirking of this sort is probably more likely in larger, more anonymous, and more bureaucratic establishments where monitoring worker behaviour is more difficult and employee attachment or involvement is lower (Dionne and Dostie 2007). One way to overcome the shirking problem is paying efficiency wage premia (see Barmby et al. 1994), and it may be no coincidence that in the German private sector higher wages than stipulated in the collective wage agreement are more likely to be found in larger establishments (see Jung and Schnabel 2011). Quite a few empirical studies have found that absenteeism tends to increase with establishment size (see, e.g., Frick and Malo 2008 for EU-14 countries and Arnold and de Pinto 2015 for 34 countries in Europe), but for Germany, the evidence is not so clear-cut (see Störmer and Fahr 2013 and Arnold et al. 2018). Nevertheless, given that establishments in the public sector are prototypical bureaucracies, are larger (Gregory and Borland 1999) and do not pay efficiency wages in Germany (Jung and Schnabel 2011), shirking can be expected to play a more important role in the public than the private sector.

Various theoretical models imply that shirking or the incentive to be absent from work is lower the higher the costs or penalties are that employees face in case of absence (see, e.g., Allen 1981, Barmby et al. 1994, and Engström and Holmlund 2007). This hypothesis is confirmed by several international empirical studies that compare the effects of different sickness benefit systems across countries (see Osterkamp and Röhn 2007, Lusinyan and Bonato 2007, Frick and Malo 2008). However, employees in Germany do not incur immediate monetary costs in case of sickness absence. From the first day of absence they get 100 percent sick pay paid by the employer, both in the private and the public sector. ${ }^{7}$ That said, in case of (excessive) absenteeism employees may face some other penalties such as reduced career opportunities and a higher likelihood of dismissal. For instance, since high absence rates may reduce the chances of obtaining a permanent contract, employees with temporary jobs like fixed-term contracts can be expected to signal effort and thus show lower absenteeism. This has been found

\footnotetext{
${ }^{6}$ When information on workers' satisfaction with income or wages is missing, some studies include workers' (relative or absolute) wages (see, e.g., Pfeifer 2010, Arnold et al. 2018). We will not make use of the wage variable since our data set provides the better-suited income satisfaction variable and since the wage variable has many missing values, so that including it would reduce our estimation sample by 17 percent.

${ }^{7}$ After six weeks of absence (when sickness insurance takes over) this share decreases to 70 percent of gross wages.
} 
to be the case in the international study by Arnold and de Pinto (2015) and in the public sector study by Bradley et al. (2014).

Concerning the penalty of dismissal, this becomes less likely the longer a worker is employed in a firm since the dismissal costs to the employer and employment protection tend to increase with tenure in many countries, including Germany. Interestingly, although tenure has been found to be positively related to worker absence in a study across 34 European countries by Arnold and de Pinto (2015), several studies for Germany do not show a statistically significant relationship (Störmer and Fahr 2013, Arnold et al. 2018). Dismissals are even more unlikely in the public sector where employees enjoy a very high employment protection in Germany. Civil servants can only be fired in case of malfeasance of office (e.g. when convicted to a prison sentence of one year or longer), and contractual employees in the public sector are difficult to dismiss if they are at least 40 years old and have been employed in the public sector for at least 15 years. ${ }^{8}$ These differences in employment protection might be associated with a higher prevalence and extent of absenteeism in the public sector.

It is common for empirical studies of absence from work to include socio-demographic characteristics of employees such as age, sex, qualification, household context and nationality as potential explanatory variables even if the theoretical basis of their inclusion is often weak (see the literature reviews by Allebeck and Mastekaasa 2004 and Beemsterboer et al. 2009, as well as Beblo and Ortlieb 2012, Störmer and Fahr 2013, and Arnold et al. 2018 for Germany). Empirical findings vary considerably and partly seem to depend on whether the crucial determinants discussed above such as health status, working conditions, and job (dis)satisfaction have also been included in the analysis. In addition to the socio-demographic composition of the workforce, structural factors like a different composition of professional activities or regional living conditions could be behind observed differences in sickness absence between the public and the private sector (Bevan 2016, Meyer et al. 2017: 290, Knieps and Pfaff 2016: 79) and should therefore be accounted for in empirical analyses.

Against this background of the theoretical and empirical literature, four hypotheses on differences in absence from work between the public and private sector can be derived that are testable with our data and have different implications for public policy:

H1. Absence from work is higher in the public sector mainly due to structural factors (like the professions and regions workers are active in) and socio-demographic characteristics (i.e. differences in workforce composition concerning age, sex, qualification etc.).

\footnotetext{
${ }^{8}$ Riphahn (2004) finds for public sector employees in Germany that reaching the more secure employment position with age 40 and tenure of 15 years results in a marked increase in annual days of absence.
} 
H2. Absence from work is higher in the public sector due to differences in workers' health status (since public employers are more socially-minded and less selective in hiring or keeping employees with a substandard health status.)

H3. Absence from work is higher in the public sector since workers take (more) sick-days to compensate for more stressful working conditions, higher emotional strain at work, and lower income satisfaction in this sector.

H4. Absence from work is higher in the public sector where shirking of "malingering bureaucrats" is more likely due to better employment protection and less monitoring than in the private sector.

Using the crude distinction between voluntary and involuntary absence from work discussed at the beginning of this section, the first two hypotheses suggest that differences between the public and private sector are mainly structural and reflect involuntary absence, suggesting they should be no serious cause for concern for public policy. In contrast, hypotheses 3 and 4 refer to voluntary absence from work as a behavioural response of workers, either to compensate for (perceived) disadvantages in wages and working conditions or to exploit institutional specifics of the public sector. Both kinds of opportunistic behaviour by employees could be addressed by public policy, e.g. by altering working conditions and the institutional framework.

\section{DATA AND DESCRIPTIVE EVIDENCE}

To study absenteeism in the public and private sector we use the $B I B B / B A u A$ Employment Survey of the Working Population on Qualification and Working Conditions in Germany 2012 (Hall et al. 2015; see Rohrbach-Schmidt and Hall 2013 for a more detailed description). This rich data set provides a representative sample of more than 20,000 individuals from the German active labour force. The survey is restricted to individuals who work at least 10 hours per week and are at least 15 years old. Its data on the incidence and the number of days of sickness absence, combined with information on individuals' subjective health status, afflictions that received medical treatment, working conditions, and job satisfaction make it suitable for our analysis. Such detailed information on the type of afflictions that received medical treatment and on workplace-related factors like stressful working conditions is not available in the GSOEP data set that has previously been used for studying absence from work in Germany (see, e.g., Thalmeier 2002, Störmer and Fahr 2013). A disadvantage of our data set is its cross-sectional nature which means that we cannot address the potential problem of selection on unobservable characteristics and do not intend to interpret our results as causal effects.

Our estimation sample consists of 15,103 individuals, 10,603 of whom work in the private sector whereas 4,500 are employed in the public sector. We exclude 
Figure 1

Distribution of absent days in the public sector and private sector. [Colour figure can be viewed at wileyonlinelibrary.com]

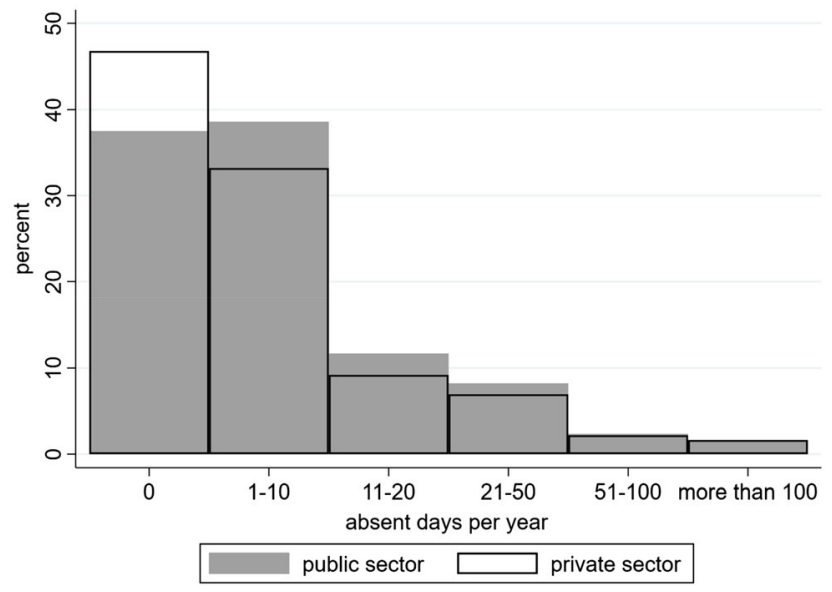

self-employed individuals as well as helping family members and freelance collaborators, as they are not found in the public sector. Furthermore, we restrict weekly working time to 60 hours per week and only include individuals between the age of 15 and 65 in the analysis.

Figure 1 presents our raw data on the number and the distribution of absent days. The histogram shows that there are distinct differences between the private and public sector. We see that 46.8 percent of workers in the private sector report zero days of sickness absence during the last 12 months, but this is only the case for 37.5 percent of public sector employees. When we focus on those individuals who were absent in the last year, it is striking that in all categories up to 50 days of absence, absent days are higher in the public than the private sector.

Concerning longer absences of more than 50 days per year, however, both sectors show a similar picture. This finding is contrary to the assertion mentioned above that the public sector is less selective in hiring or keeping contractual employees with respect to their health status and capabilities (Oppolzer 1999), which would imply that individuals with more than 50 days of sickness absence per year are more often found in the public sector. In this context it should be kept in mind (and accounted for in the following estimations) that long periods of absence may be due to exogenous factors such as serious illnesses and thus may reflect different determinants of absenteeism than short periods of absence. ${ }^{9}$

\footnotetext{
${ }^{9}$ Note that although our data set provides information on the incidence and number of occasions of sickness absence as well as on the total number of workdays lost, we do not know the length of each spell of absence. Nevertheless, in our estimations we will perform a robustness check with a reduced sample excluding workers with more than 50 days of absence per year (see Appendix Table 2).
} 
Focusing on our main variable of interest, namely the incidence of sickness absence, we see that 62 percent of respondents from the public sector report that they stayed home sick or called in sick at least once during the last 12 months. In contrast, this was only the case for 53 percent of private sector employees (see Table 1). Looking at the number of occasions of sickness absence, this is also somewhat higher in the public than the private sector (1.22 vs. 0.93$)$. The difference is even more pronounced for the average number of workdays lost due to sickness absence, which amount to 11.35 days in the public sector and 10.11 days in the private sector. ${ }^{10}$ The fact that all three absenteeism indicators are statistically significantly higher for public sector employees thus seems to be consistent with the stereotype of the "malingering bureaucrat".

The differences in the average numbers of occasions and days of absence between sectors partly reflect the fact that many more private than public sector employees state that they never stayed home sick in the previous year. When looking at those employees who were absent at least once in the last 12 months, the differences between the public and the private sector become more blurred: Although there remains a higher average number of sickness occasions in the public sector (1.95 compared to 1.75), the conditional number of workdays lost due to sickness absence is now somewhat higher in the private sector. These findings suggest that behavioural differences between public and private sector employees are more pronounced in the incidence and occasions than in the workdays lost due to sickness absence.

As stated in hypothesis 1, the higher absence from work in the public than the private sector may simply reflect structural and socio-demographic differences between the sectors. Table 1 shows that the shares of women and of university graduates are much higher in the public sector, and employees are on average older than their private sector counterparts. These patterns are well established in the literature (see, e.g., Blank 1985, Dustmann and van Soest 1998, Maczulskij 2017). It can also be seen that the share of individuals with a migration background is lower in the public than in the private sector. However, the higher absenteeism in the public sector could also reflect differences in employees' health status (hypothesis 2) and/or different behaviour in case of healthiness (hypotheses 3 and 4).

Starting with health status, it is possible that those people working in the public sector are simply not as healthy as their counterparts in the private sector and thus are absent from work more often. To tackle this question, we can make use

\footnotetext{
${ }^{10}$ The overall figures for the incidence and length of sickness absence in our data set are in the same ballpark as those reported in the GSOEP (see Arnold et al. 2018, Table A1, although they do not distinguish between the public and private sector). We are aware that our sick-leave data (like those of the GSOEP) might suffer from recall and reporting bias. However, this would only be a problem for our analysis if this bias systematically differs between employees in the private and public sector. We have no reason to believe that this is the case.
} 
ABSENCE FROM WORK IN THE PUBLIC AND PRIVATE SECTOR




of the rich information on health in our dataset which includes a question on individuals' subjective health status, answered on a five-point Likert scale, as well as information on the types of afflictions that received medical treatment in the last 12 months. ${ }^{11}$ As can be seen in Table 1, 84 percent of employees in the public sector report at least good health status (i.e. they describe their health status as being excellent, very good, or good). This figure is almost identical in the private sector where 85 percent of workers have this health status, so that at first sight health does not seem to be the main reason for the higher incidence of sickness absence in the public sector. However, looking at the medical treatments received, individuals in the public sector report on average 2.34 different types of treated afflictions whereas this figure is only 1.90 in the private sector, and this difference is statistically significant.

Focusing now on the behaviour in case of healthiness, the literature sketched in section II emphasises the impact of working conditions such as workload or emotional strain. Our survey contains the question whether the respondents usually cope with their workload or whether they feel over- or under-challenged. Table 1 shows that on average 25 percent of individuals working in the public sector state that they perceive their workload as over-challenging whereas this is the case only for 18 percent of employees in the private sector. Individuals were also asked whether there are situations of emotional strain in or because of their job. In the private sector, on average 41 percent of workers answer in the affirmative whereas this figure is much higher in the public sector where 60 percent of employees experience emotional strain at work. The number of stressful working conditions reported by employees is also slightly higher and the support received from the direct supervisor is slightly lower in the public sector. These four findings indicate that working conditions in the public sector could be less favourable and thus may help to explain the higher absence from work in this sector. In contrast, the ability of taking family and private interests into account when scheduling working time is somewhat more prevalent in the public sector, and there is virtually no difference between the sectors in terms of weekly working hours, with individuals working on average 37.81 hours per week in the public and 37.88 hours per week in the private sector.

Job dissatisfaction could be another factor worth considering. However, descriptively there is no difference in general job satisfaction between the public and the private sector, with on average 93 percent of employees in both sectors stating that they are satisfied or very satisfied with their job (see Table 1). Looking at the more specific variable satisfaction with income, the data show only a slight difference between the sectors. While in the private sector 72 percent of employees are (very) satisfied with their income, this figures slightly

11 Information on medical treatment was collected for 24 different types of afflictions, e.g. headaches, depression, low back pain, eye problems, sleeping disorders, and physical exhaustion. 
increases to 76 percent in the public sector. Thus, the potential of job and income satisfaction for explaining different incentives of being absent seems to be limited.

Finally, looking at some variables that could be related to shirking behaviour, we find substantial differences in establishment size and average tenure between the sectors. As expected, the public sector has a higher share of larger establishments (with 100 or more employees). ${ }^{12}$ Concerning tenure, the probability of dismissal is usually negatively correlated with tenure (see section II), so that systematic differences in tenure between the sectors could contribute to differences in absence behaviour. A look at the data points to the relevance of this variable since average tenure in the public sector is 17.20 years and thus almost 5 years higher than in the private sector with its 12.49 years. This could lead to a lower probability of dismissal in the public sector, making absence less risky for the employees compared to the private sector. In contrast, there is no significant difference in the share of fixed-term contracts between the public and private sector.

\section{ECONOMETRIC ANALYSIS}

The descriptive evidence discussed above has indicated that the difference in the average number of occasions and days of absence between public and private sector employees is partly driven by the fact that in the private sector more employees never stay home sick whereas in the public sector many employees report positive numbers of sickness absence. It seems sensible to take this pattern into account when analysing the absenteeism of both groups and we thus estimate hurdle regression models. ${ }^{13}$ These models comprise two functionally independent parts: a binary model dealing with zeros, and a truncated count data

\footnotetext{
${ }^{12}$ If larger plants are more likely to be insured against production losses resulting from (sickness) absence or if they get more easily replacements for long-time absent workers (thus decreasing workers' reluctance to stay away from work), this may result in higher average absenteeism in the public sector. Unfortunately, our data do not allow us to test this potential explanation suggested by a reviewer.

${ }^{13}$ Since Poisson models are not regarded as appropriate (because the Poisson distribution does not suit the typically over-dispersed absence data), in the health econometrics literature it is common to use the hurdle model, also called two-part model (see Møller Pedersen and Skagen 2014, who discuss various methods). Possible alternatives would be the zero-inflated negative binomial model or the Tobit model. The zeroinflated negative binomial model (see Long and Freese 2006: ch. 8.6) assumes that there exist "excessive zeros", which means that it is impossible to have strictly positive numbers of absence for some individuals, for example because these individuals were not in the workforce. Since we only look at individuals from the active labour force population, such "excessive zeros" are unlikely to occur and thus the hurdle model seems to be more appropriate. The Tobit model (see Wooldridge 2010: ch. 17) is a convenient choice for modelling corner solutions where the dependent variable takes on the value zero with positive probability but is a continuous random variable over strictly positive values. However, it implicitly assumes that the data generating process determining the zero outcome (never sick) is the same as the process determining the positive outcome (days of absence), which need not be true in the case of sickness absence.
} 
model for the number of events conditional on having a strictly positive number of events (see, e.g. Long and Freese 2006: ch. 8.5). Consequently, our multivariate analysis proceeds in two steps. We first focus on the difference in the probability of having ever been absent between public and private sector employees, running probit regressions. In a second step, we then look at the number of absence days conditional on ever having been absent, using truncated negative binomial regressions. In addition, as a check of robustness we estimate both models jointly by running a Tobit specification (despite the problems mentioned in footnote 13).

Table 2 shows the probit regression results (average partial effects) of the probability of ever having called in or stayed home sick in the last 12 months. In the first column we estimate a pooled model not accounting for differences in observable characteristics which indicates that the probability of ever having been absent is 9.3 percentage points higher for public sector than for private sector employees. This is in accordance with the descriptive evidence in Table 1.

In the next columns of Table 2 we stepwise add several groups of variables to account for observable differences between employees and workplaces in the private and public sector that are often believed to be behind the difference in sickness absence and that correspond to our four hypotheses. We want to find out whether and to which extent these groups of variables can explain the 9 percentage points difference that shows up in column 1 and in the descriptive comparison of private and public sector employees in Table 1.

We start with a block of structural and socio-demographic factors (hypothesis 1). We include 54 dummies for the professional fields employees are working in since health risks usually differ across professional fields, so that differences in sickness absence between the public and the private sector could simply reflect a different composition of professional activities (Bevan 2016, Meyer et al. 2017: 290). We also add 16 dummies for the German federal states that crudely reflect regional living conditions since descriptive analyses by sickness funds (such as Knieps and Pfaff 2016: 79) indicate considerable regional differences in sickness absence. As the estimation results in column 2 of Table 2 show, the professional fields dummies and the federal states dummies are each jointly statistically significant. ${ }^{14} \mathrm{We}$ further include socio-demographic variables like sex, age (three age group dummies to account for a potentially non-linear relationship), migration background, professional qualification, and family background (partner, young children) in the analysis. Recall from Table 1 that the average values of most of these variables differ considerably between public and private sector employees, and it is sometimes argued that differences in demographics like the higher share of women and of older workers are largely

\footnotetext{
${ }^{14}$ Note that our insights do not change when we restrict our sample to those 44 professional fields where both employees from the private and from the public sector are present.
} 
ABSENCE FROM WORK IN THE PUBLIC AND PRIVATE SECTOR

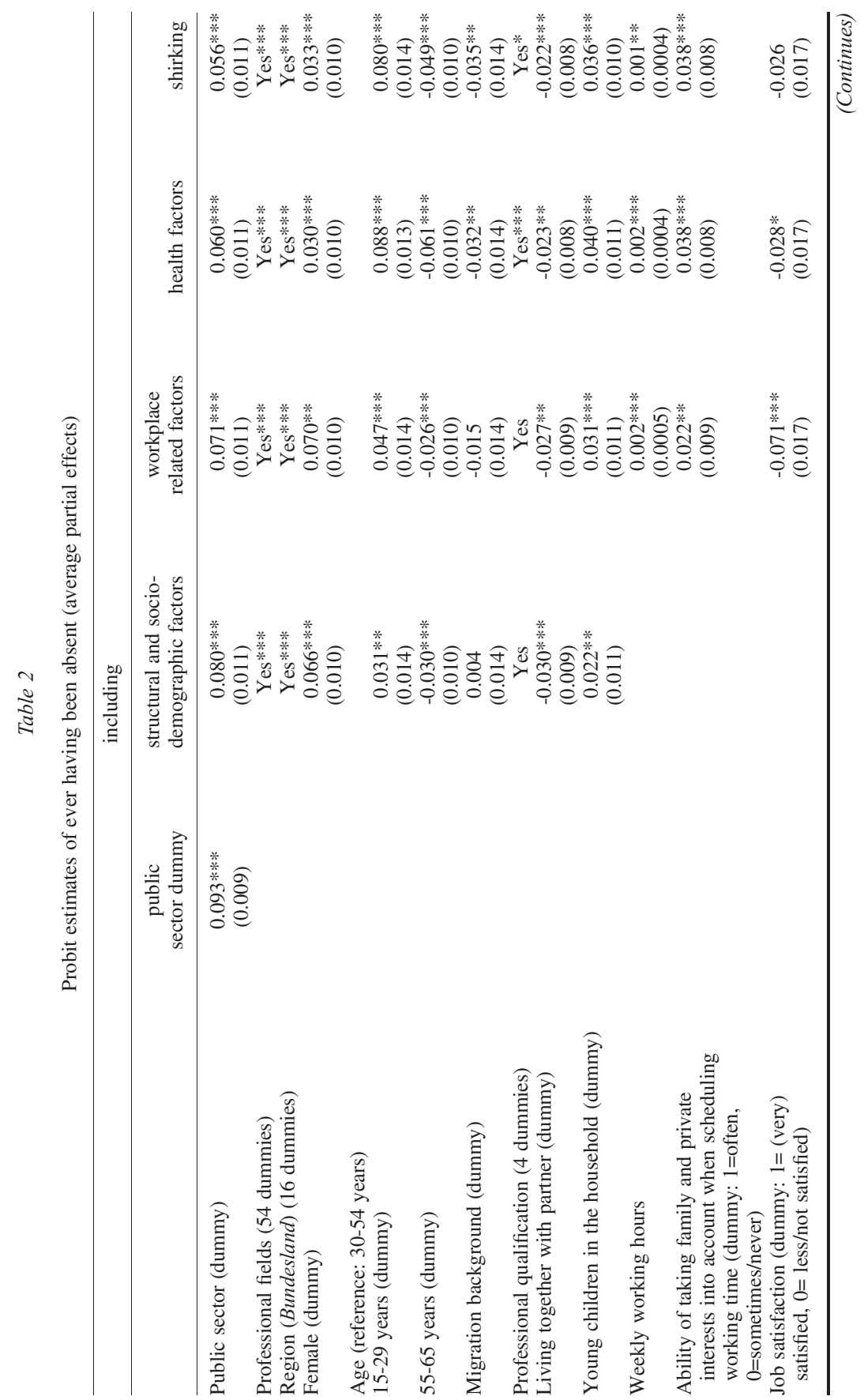


STEPHANIE PRÜMER/CLAUS SCHNABEL




ABSENCE FROM WORK IN THE PUBLIC AND PRIVATE SECTOR

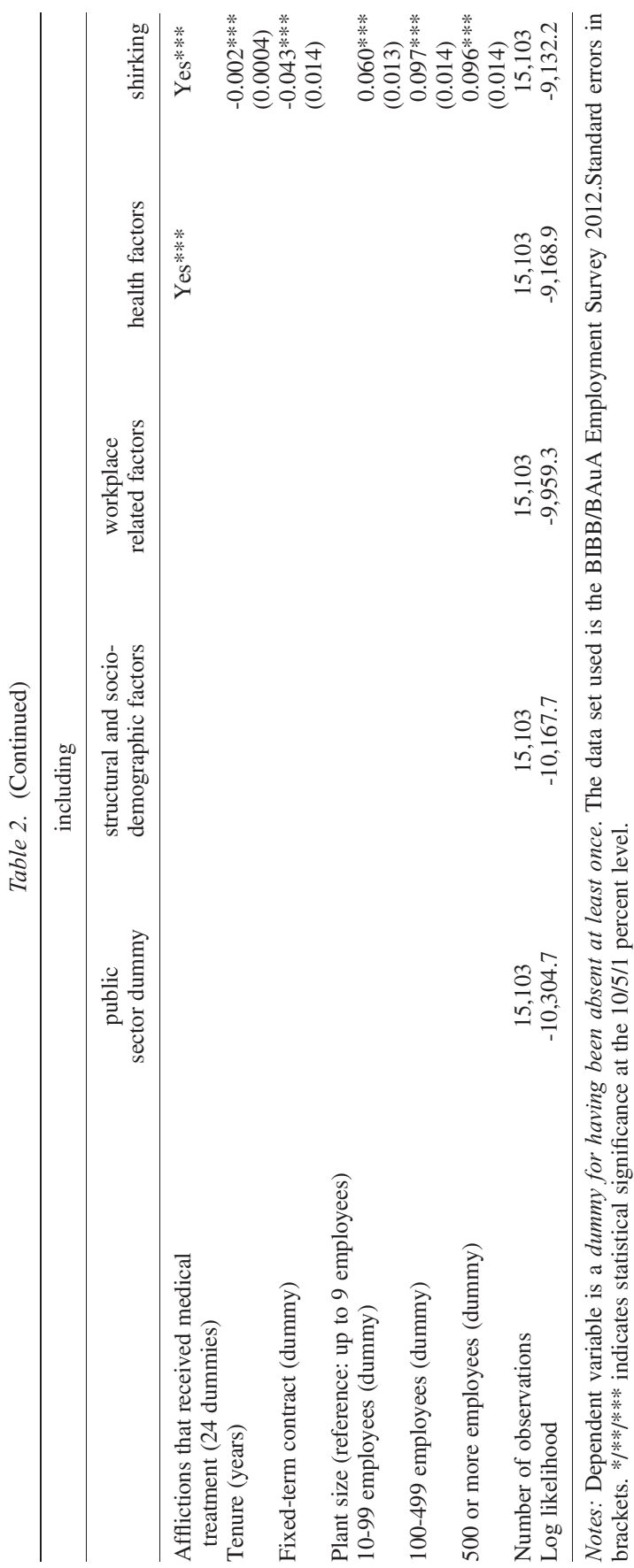


responsible for the differences in average sickness absence (see, e.g., Oppolzer 1999, Bevan 2016). Our estimation results in column 2 of Table 2 show that not all of these socio-demographic variables are statistically significant. Moreover, the average partial effect of the public sector dummy is only moderately reduced to 8.0 percentage points when including the first block of variables. This finding suggests that - in contrast to hypothesis 1 - the difference in sickness absence between the public and the private sector is not mainly due to structural and socio-demographic factors.

Next, we account for working conditions (discussed in section II) by including weekly working hours, a dummy indicating whether one is often able to take family and private interests into account when scheduling working time, two dummies for job and income satisfaction, two dummies indicating whether the workload is over- or under-challenging, a dummy indicating emotional strain at work, a dummy indicating whether employees receive support from their direct supervisor, and a summary index comprising 23 stressful working conditions, such as noise, dirt, coldness, dazzling light, repetitive work, or high time pressure. Our estimation results in column 3 of Table 2 show that most of these variables are statistically significantly related to the probability of absence from work. Moreover, the magnitude of the public sector dummy is slightly reduced when adding the block of working condition variables. These findings seem to be consistent with our hypothesis 3 .

That said, the magnitude and the statistical significance of the working conditions variables is substantially reduced in column 4 when we take health status into account, a possible determinant of (sickness) absence strongly emphasized in the medical statistics literature. Obviously, health and working conditions are related in that workers' bad health status might be a consequence of bad and dangerous conditions at the workplace. ${ }^{15} \mathrm{We}$ include four dummies for self-assessed health status and 24 dummies for each affliction that received medical treatment in the last 12 months. Our estimation results indicate that health variables are indeed highly significantly related to absenteeism, even when accounting for working conditions. They also show that the sector difference in the probability of sickness absence is reduced to 6.0 percentage points when accounting for employees' health, which seems to be worse among public sector employees. This result can be interpreted as supporting our hypothesis 2 .

\footnotetext{
${ }^{15}$ This connection gives rise to the so-called bad-control problem (see Angrist and Pischke 2009, ch. 3.2.3): When including health as an additional control variable, we (partly) shut down the direct channel between working conditions and sickness absence visible in column 3 . We nevertheless decided to present a comprehensive specification of our empirical model including health status in Tables 2-4 since our main interest is taking account of all potential determinants of sickness absence suggested by various disciplines for explaining differences between the public and private sector. In addition, we will re-estimate the model excluding health status in Appendix Table 1 and check whether this affects our major insights.
} 
Finally, in the last column we add three variables that according to our theoretical considerations in section II should be related to (and thus serve as crude proxies for) employees' shirking behaviour. These are tenure, the existence of a fixed-term contract, and the size of the establishment. As expected, the probability of having been absent from work in the last 12 months is significantly lower in case of a fixed-term contract and when working in a smaller plant. In contrast, the relationship with tenure shows an unexpected negative (but relatively small) coefficient. Since adding these three variables only reduces the magnitude of the public sector dummy by 0.4 percentage points and since the crucial tenure variable has an unexpected sign, these findings provide only partial support for our shirking hypothesis 4 . That said, our empirical approach is likely to underestimate the relevance of shirking since shirking behaviour is not directly observable in our data and we only can account for some observable conditions that may affect shirking.

Interestingly, even with the full set of explanatory variables, the probability of ever having been absent is still 5.6 percentage points higher in the public sector, and this difference is statistically significant at the 1 percent level. ${ }^{16}$ Observable differences between employees and workplaces in the private and public sector thus do not fully explain the difference in the incidence of sickness absence.

After studying the incidence of absence from work we now focus on the extent of absenteeism, as measured in the number of working days lost. Instead of analysing the total number of days of absence for all employees (including those who were never absent), we only look at the working days lost of those employees who actually were absent at least once. This takes into account that the difference in the average number of absence days between public and private sector employees is partly driven by the fact that fewer private sector employees report absence days different from zero, whereas many more public sector employees report positive numbers of days of absence. Focusing only on those persons who ever were absent reduces our estimation sample to 8,455 observations.

Table 3 shows the results of truncated negative binomial regressions for the number of absent days of those employees who were absent at least once. ${ }^{17}$ We stepwise include the same explanatory variables as in Table 2. Conditional on ever having been absent from work, the extent of absence is on average 0.72 days lower for public than for private sector employees, although this

\footnotetext{
${ }^{16}$ Using pooled GSOEP data for the years 2001, 2006 and 2011, Arnold et al. (2018) report a larger difference in sickness incidence of 11.6 percent between public and private sector employees.

${ }^{17}$ Note that the results of these regressions should be interpreted cum grano salis. Conditioning on strictly positive numbers of days of absence can result in a selection bias (see Angrist and Pischke 2009: 99-102) unless the incidence and the extent of absenteeism are independent (after controlling for observable factors). Unfortunately, our data set does not contain variables which could serve as convincing exclusion restrictions in a selection correction model.
} 
STEPHANIE PRÜMER/CLAUS SCHNABEL




ABSENCE FROM WORK IN THE PUBLIC AND PRIVATE SECTOR

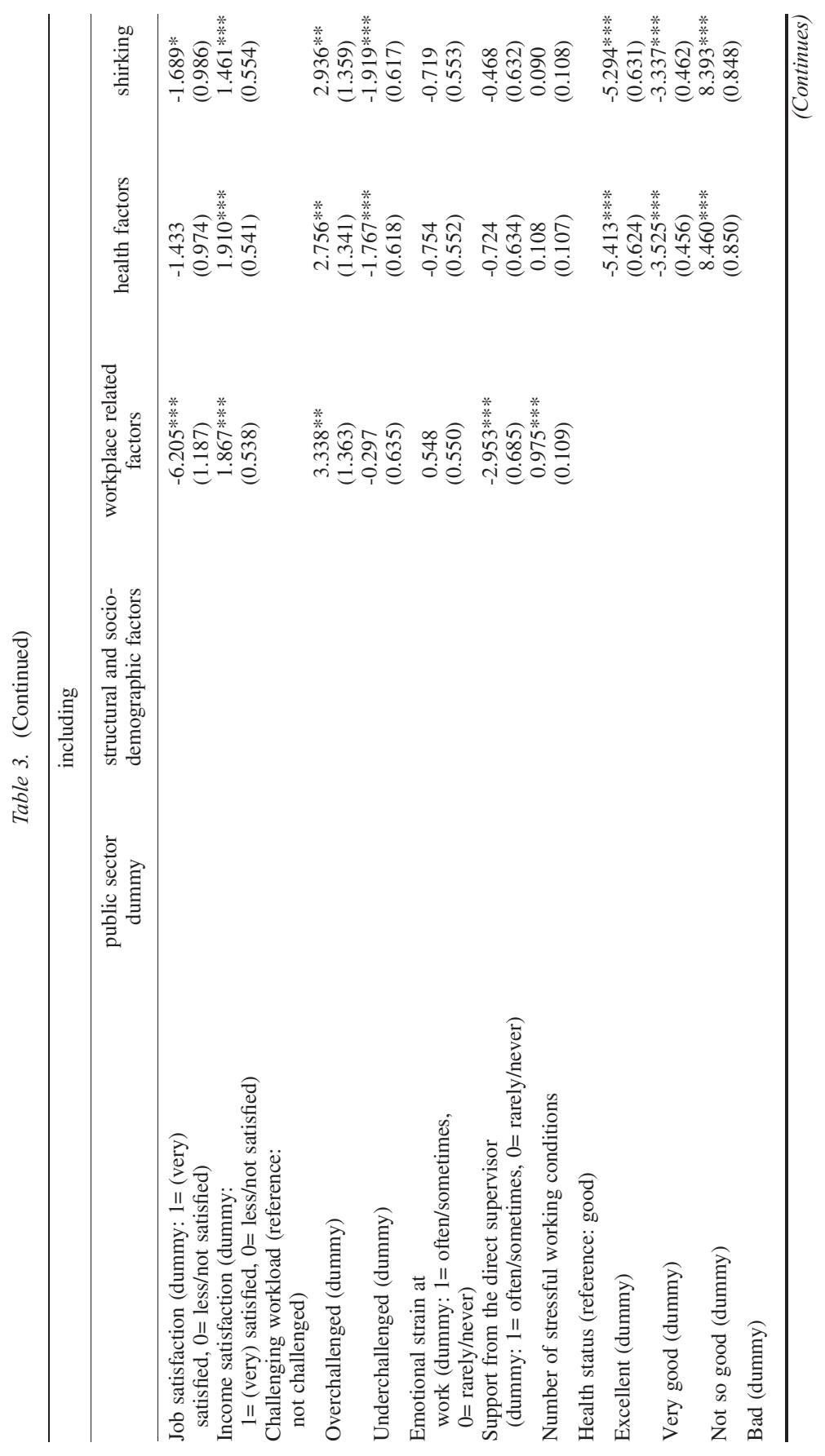


STEPHANIE PRÜMER/CLAUS SCHNABEL

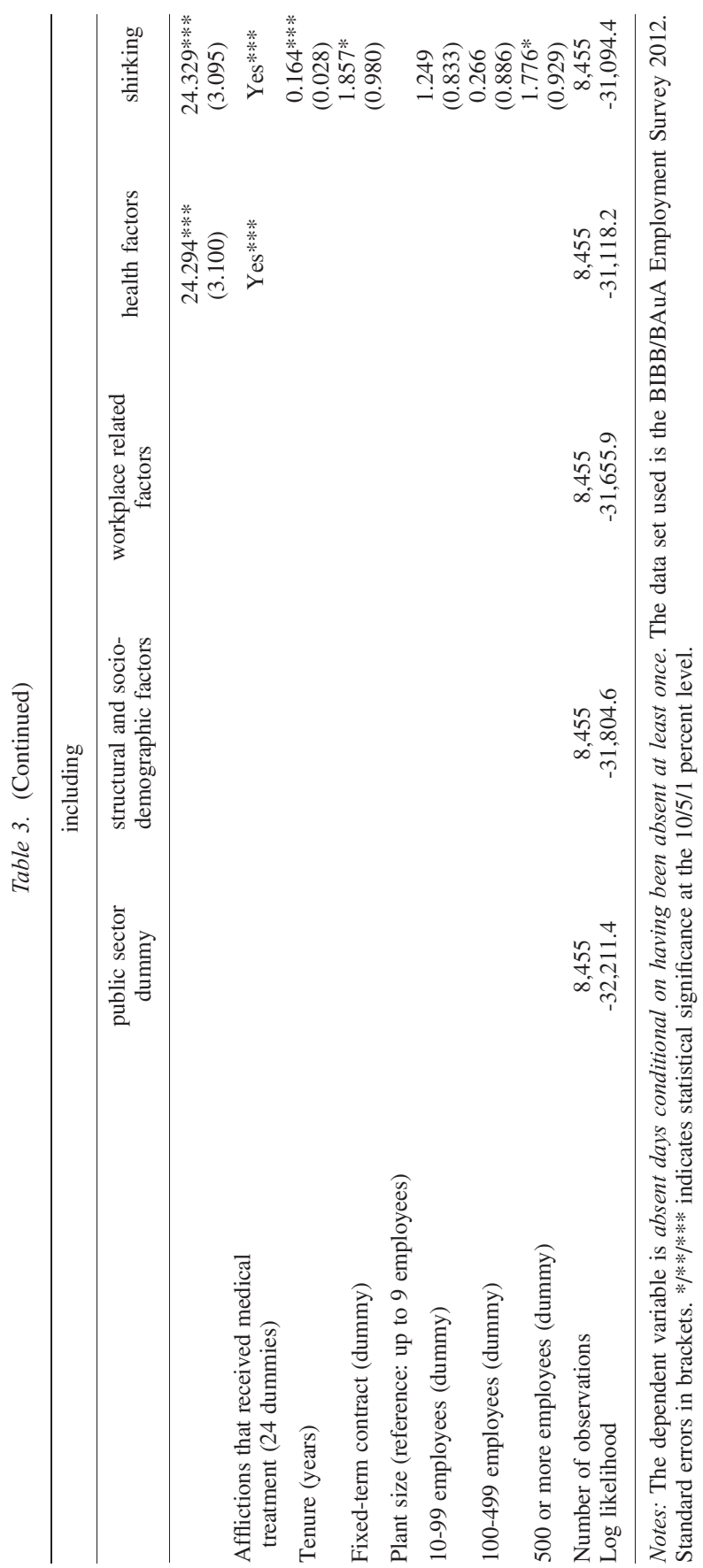


difference is not statistically significant (column 1). This insignificance does not change when including our four blocks of explanatory variables, so that there is no difference between public and private sector employees in the number of working days they are away sick.

In order to have a closer look at the partial effects of the explanatory variables and examine whether the statistically significant variables play different roles in the public and the private sector, we now run separate regressions for employees in these two sectors. The results of these separate regressions both for the probit and the truncated negative binomial model are displayed in Table $4 .{ }^{18}$

Starting with the group of structural and socio-demographic variables we see that age shows a statistically highly significant, non-linear association with work absence both in the public and the private sector. Interestingly, it is negatively related to the probability of ever having been absent, whereas it is positively related to the number of days absent from work (which might be a consequence of endogenous selection). This result confirms previous findings in the literature that older people are absent less frequently, but if they call in sick, they are usually absent for a longer period of time (see, e.g., Thalmeier 2002, Lechmann and Schnabel 2014, Meyer et al. 2017: 294). ${ }^{19}$ Both in the private and (measured less precisely) in the public sector, individuals with a migration background are less likely to be absent and record considerably fewer days of sickness absence. In contrast to the descriptive evidence in Table 1 and in sickness fund reports (like Knieps and Pfaff 2016: 51-53), gender differences in absenteeism do not seem to play a statistically significant role when controlling for age, health status, workplace-related factors, job satisfaction etc. (with the small exception of absenteeism incidence in the private sector). Both living together with a partner and having young children in the household is statistically significantly related to the probability of absence in the private sector, but the estimated coefficients of these variables are insignificant in the public sector.

When next interpreting the group of workplace-related variables, we must take account of the relationship of variables like working conditions and worker satisfaction with workers' health discussed above. Since only looking at the estimation results of the full model that includes health variables in Table 4 may obscure some relationships, we also present the results of models estimated excluding health variables in Appendix Table 1. Looking across the group of workplace-related variables, we see that not all average partial effects are

\footnotetext{
${ }^{18}$ The following findings are consistent with the results of fully interacted OLS models not reported here (but available on request) which also show that the partial effects of virtually all explanatory variables do not significantly differ between the public and the private sector (at the 5 percent level).

${ }^{19}$ The latter relationship may reflect medical reasons (such as serious illnesses that are more likely to show up in the oldest age group). It is also consistent with an argument by Bauer and Eichenberger (2018) that absence behaviour is related to workers' time remaining until their retirement, so that the age group closest to retirement shows the highest days of absence.
} 
STEPHANIE PRÜMER/CLAUS SCHNABEL




ABSENCE FROM WORK IN THE PUBLIC AND PRIVATE SECTOR

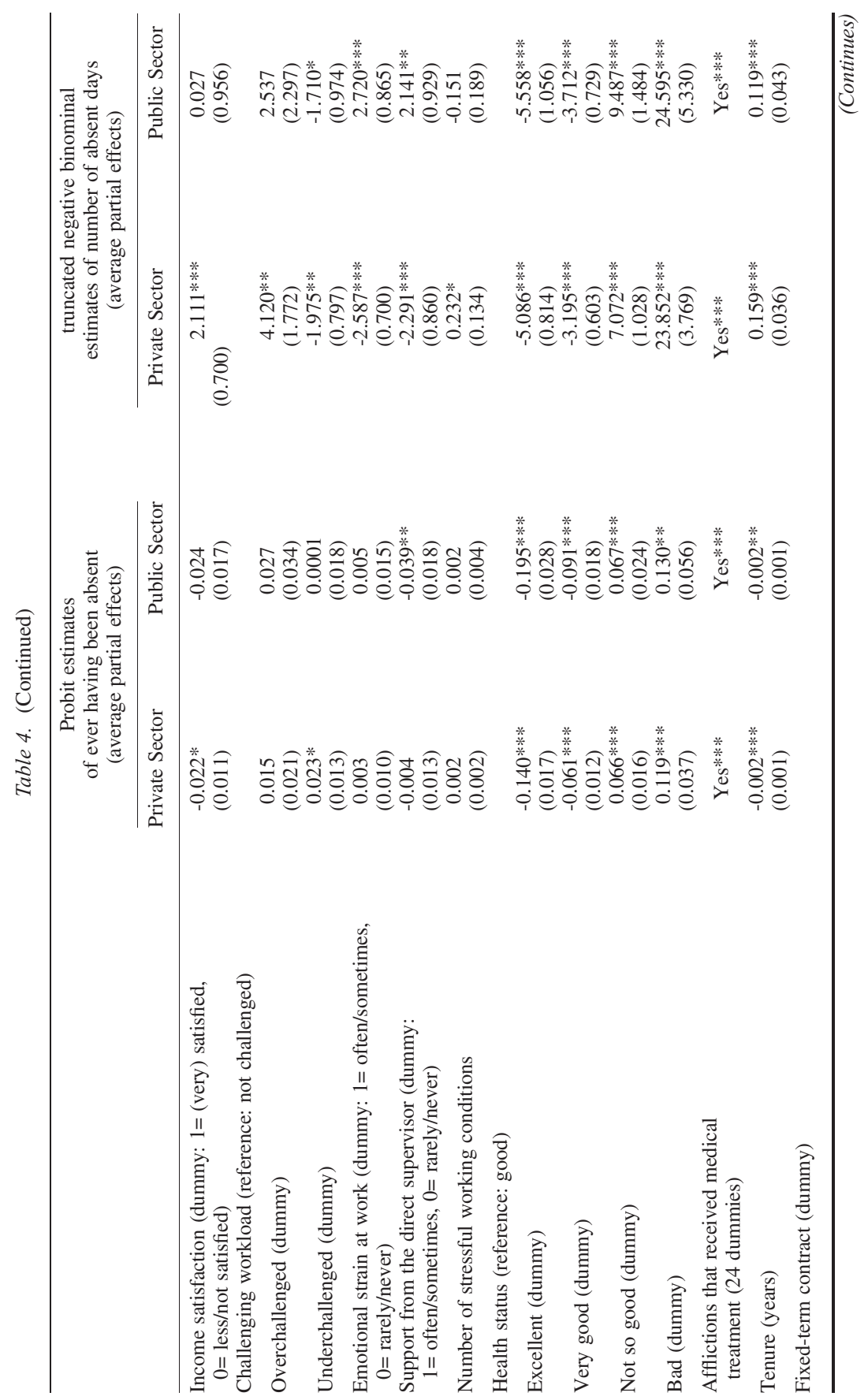


STEPHANIE PRÜMER/CLAUS SCHNABEL

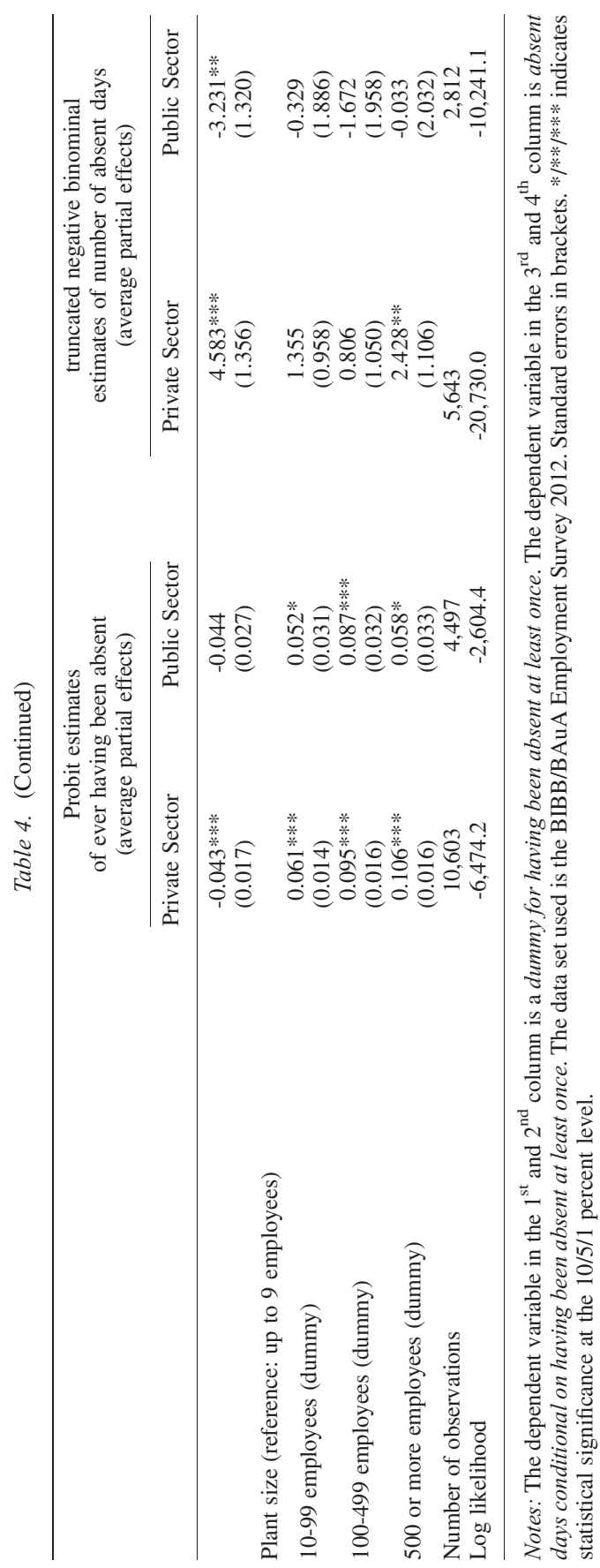


statistically significant, and some variables show an unexpected relationship with sickness absence. A case in point is individuals' ability of taking family and private interests into account, which seems to be positively related to absence from work in both sectors. This finding is at odds with the neoclassical theory of labour-leisure choice, but it has been found before in the literature (see Dionne and Dostie 2007 and Lechmann and Schnabel 2014). In accordance with this theory and with considerations from occupational medicine, longer weekly working hours are associated with a slightly higher probability and higher days of absence, but these relationships are not estimated very precisely.

Job and income satisfaction seem to be of similar importance for absenteeism in the public and private sector, although their average partial effects usually do not reach conventional levels of statistical significance once health variables are included (as in Table 4). As expected, employees who are satisfied with their job tend to have a lower probability of absence from work and fewer days of absence. Concerning income satisfaction, the incidence is similar but the relationship with the number of days is less clear. In both sectors, an over- and an underchallenging workload is positively related to the incidence of sickness absence, but only the estimation coefficient of being underchallenged reaches conventional levels of statistical significance in the private sector. Whereas being overchallenged is associated with higher days of absence, feeling underchallenged is associated with fewer days of absence (conditional on being absent at all).

The number of stressful working conditions is positively related to the incidence and the days of absence in both sectors, but these relationships only become statistically significant if health status is excluded from the model (in Appendix Table 1). If the health variables are excluded, emotional strain at work also significantly increases the probability of ever having been absent in both sectors, but its relationship to the number of absence days is positive in the public sector and negative in the private sector. Individuals who get support from their direct supervisor are less likely to be absent from work (in particular if the health variables are excluded), but conditional on being absent this support is associated with an increase in the number of days absent in the public sector whereas it decreases the number of absence days in the private sector.

Moving on to the health variables, it is apparent that an excellent or very good state of health (compared to the reference category of good health) is associated with a lower incidence and fewer days of absence from work in both sectors. Correspondingly, bad health increases the probability of absence by about 12 percent in the private and 13 percent in the public sector, and it raises the extent of absence by approximately 24 days in both sectors. The dummies for subjective health status and for medical treatments received are jointly statistically significant at the 1 percent level for public as well as for private sector employees. For the health status dummies, the confidence intervals of the average partial 
effects for both sectors overlap, suggesting that they are not statistically significantly different (which is confirmed in a fully interacted model estimation).

Our theoretical considerations in section II suggested that employees with temporary jobs try to signal effort and thus show lower absenteeism. As expected, the existence of a fixed-term contract reduces the probability of staying home sick by more than 4 percent in both sectors (even if this association narrowly misses conventional levels of statistical significance in the public sector). Surprisingly, however, conditional on being absent it increases the number of days absent in the private sector whereas it decreases the number of absence days in the public sector. In both sectors, tenure unexpectedly shows a small negative association with the probability of absence whereas it is positively related to the number of days absent (as expected). The plant size dummies are jointly statistically significant for the probability of absence in both sectors. Although at first sight the patterns of the relationship seem to differ between the public and the private sector, the large confidence intervals of the average partial effects for both sectors overlap, indicating that they are not statistically significantly different. Consistent with a shirking interpretation, we find that in both sectors individuals in small plants with up to 9 employees (our reference category) are much less likely to be absent than employees in larger plants.

All in all, our analyses show that individuals' health, age, migration background, weekly working hours, working conditions, job and income satisfaction as well as the size of the plant they work in and the existence of a fixed-term contract are important factors associated with the incidence of absence from work. These factors are of similar magnitude in the public and private sector, although they are typically estimated less precisely in the smaller public sector sample. Our results are less clear concerning the relationships of these variables with the number of days of absence (conditional on having been absent at least once), where the sign and the statistical significance of the average partial effects sometimes differ between the public and the private sector. That said, it is again health, age, migration background, working hours and working conditions as well as tenure and a challenging workload that appear to be associated with the extent of work absence in both sectors. By and large, we may conclude that the absence behaviour of public and private sector employees is related to the same variables and that our estimations do not provide a clear and simple explanation for the higher incidence of work absence in the public sector.

As discussed in section III, it could be possible that our results are influenced by workers who record very long absences from work. Although we do not have information on the length of individual spells of absence in our data set, we can partly take account of this potential problem by excluding those workers from our estimation sample whose total number of absent days in the last twelve months is particularly large. The results of such an exercise, where workers with more than 50 days of absence are excluded from the sample, are shown in 
Appendix Table 2. It can be seen that such a restriction does not substantially affect our results and insights. The same applies when restricting the sample to workers who have not more than 20 days of absence (results are available on request).

Note that our insights still hold when performing a number of additional robustness checks (results of which are available on request). For instance, we restricted our sample to those 44 professional fields where both employees from the private and from the public sector are present. We also divided our sample of public sector employees into civil servants and contractual employees. The shares of employees who report ever having been absent are similar in both groups, but the number of absence days is substantially higher for contractional employees (who are more often blue-collar workers). Nevertheless, the estimation results of the hurdle model for the incidence and extent of absenteeism are quite similar for both groups of employees. We further conducted separate estimations for men and women, and we excluded blue-collar workers from our sample (who are more often found in the private sector and who do not fit the stereotype of malingering bureaucrats). Finally, we replaced our two-step hurdle model by a Tobit model even if this frequently used model does not seem to be optimal when the sign of the relationship with a variable like age differs between the first and the second step. However, this did not change our main conclusions concerning the other variables and relationships.

\section{CONCLUSIONS}

Scrutinising the stereotype of the "malingering bureaucrat", this paper has compared and analysed absence from work in the public and private sector. Using a large representative data set for Germany, we have found that absenteeism seems indeed to be more prevalent in the public sector. Whereas only 53 percent of private sector employees report having been absent at least once in the past 12 months, this figure is 9 percentage points higher for public sector employees. Related, on average public sector employees record one more day of absence per year compared to workers in the private sector. Although these differences showing up in descriptive statistics are substantially reduced and partly disappear when controlling for individuals' socio-demographic characteristics, health status, professional activities, and for workplace-related factors, the probability of staying home sick at least once a year is still 5.6 percentage points higher in the public sector, ceteris paribus.

A closer investigation has shown that the same variables do play a role for absenteeism both in the public and the private sector. Differences in the composition of the workforce (e.g., w.r.t. employees' health, age, and sex), in professional fields, in working conditions, in tenure and in other workplace-related characteristics of public and private sector employees are not able to fully explain 
the gap in absenteeism. This finding refutes some of our hypotheses that are based on popular assertions found in the literature (see, e.g., Oppolzer 1999 and Bevan 2016).

The fact that our estimations do not provide a clear and simple explanation for the higher incidence of work absence in the public sector gives rise to the question what may lie behind this phenomenon. A limitation of our data set is that that it is only cross-sectional, so that unobserved heterogeneity cannot be taken into account. We may not rule out that public and private sector employees differ in unobservable factors like motivation, commitment, and loyalty towards their employer and their co-workers. We also do not have information on workers' risk aversion. Although there is some literature arguing that more risk averse workers tend to sort into the public sector (e.g., Pfeifer 2011, Buurman et al. 2012), it is an open question how this might affect attitudes towards sickness and absenteeism. Even though workers voluntarily chose their sector of employment and should know what to expect in terms of working conditions, the (unobserved) highly bureaucratic nature of the public sector might be another factor resulting in higher absenteeism (though we controlled for job satisfaction). It could also be the case that public employers exert less pressure on employees not to call in sick (for instance because they are not so exposed to market pressure), which would be unobservable to us.

Finally, shirking and moral hazard problems may play a more important role in the public sector, where employers show a "relaxed attitude" (Blázquez Cuesta 2012: 6) towards absenteeism and where employees enjoy high job security. We were only able to control for differences in age and tenure, which are related to employment protection. Effective job security in the public sector, however, goes beyond this since civil servants are virtually undismissable and since employers usually are very reluctant to fire contractual employees who are absent or misbehaving (but are protected by strong unions and staff councils). That said, given that the difference in the probability of sickness absence between similar public and private sector employees is less than 6 percentage points and that there is no difference in the (conditional) days of absence, the stereotype of the "malingering bureaucrat" seems to be an exaggeration, at least for Germany. Future research may be able to shed more light on this issue by conducting panel analyses of employees who switch between the public and the private sector and investigating whether this switch affects their absence behaviour.

\section{REFERENCES}

Allebeck, Peter and Arne Mastekaasa (2004). Chapter 5. Risk factors for sick leave - general studies, Scandinavian Journal of Public Health 32 (Suppl 63): 49-108.

Allen, Steven G. (1981). An Empirical Model of Work Attendance, Review of Economics and Statistics 63 (1): 77-87. 
Angrist, Joshua D. and Jörn-Steffen Pischke (2009). Mostly harmless econometrics. An empiricist's companion. Princeton: Princeton University Press.

Arnold, Daniel and Marco de Pinto (2015). How are work-related characteristics linked to sickness absence and presenteeism? Theory and data, Schmollers Jahrbuch 135 (4): 465-498.

Arnold, Daniel, Tobias Brändle and Laszlo Goerke (2018). Sickness Absence and Works Councils: Evidence from German Individual and Linked Employer-Employee Data, Industrial Relations 57 (2): 260-295.

Barmby, Tim, Marco G. Ercolani and John G. Treble (2002). Sickness Absence: An International Comparison, Economic Journal 112 (June): F315-F331.

Barmby, Tim, John G. Sessions and John G. Treble (1994). Absenteeism, efficiency wages and shirking, Scandinavian Journal of Economics 96 (4): 561-566.

Barreix, Claude (2012). Fight against absenteeism in the public service in France and the United Kingdom: Towards a comprehensive approach of the problem, International Journal of Human Resource Studies. 2 (3): 98-105.

Bauer, Ann Barbara and Reiner Eichenberger (2018). Worsening Workers' Health by Lowering Retirement Age: The Malign Consequences of a Benign Reform, CREMA Working Paper 2018-02, Center for Research in Economics, Management and the Arts, Zurich.

Beemsterboer, Willibrord, Roy Stewart, Johan Groothoff and Frans Nijhuis (2009). A literature review on sick leave determinants (1984-2004), International Journal of Occupational Medicine and Environmental Health 22 (2): 169-179.

Beblo, Miriam and Renate Ortlieb (2012). Absent from work? The impact of household and work conditions in Germany, Feminist Economics 18 (1): 73-97.

Bevan, Stephen (2016). Do public sector workers really take more sick leave? The Conversation, 11 January 2016, https://theconversation.com/do-public-sector-workers-really-take-more-sick-leave52505 (accessed 20 October, 2017).

Blank, Rebecca M. (1985). An analysis of workers' choice between employment in the public and private sectors, Industrial and Labor Relations Review 38 (2): 211-224.

Blázquez Cuesta, Maite (2012). Sickness absence rates in Spain - Evidence for the period 1996-2004, Cuadernos de Economia 35: 1-8.

Böckerman, Petri and Pekka Ilmakunnas (2008). Interaction of working conditions, job satisfaction, and sickness absences: Evidence from a representative sample of employees, Social Science \& Medicine 67 (4): 520-528.

Bradley, Steve, Colin Green and Gareth Leeves (2014). Employment protection, threat and incentive effects on worker absence, British Journal of Industrial Relations 52 (2): 333-358.

Brown, Sarah and John G. Sessions (1996). The Economics of Absence: Theory and Evidence, Journal of Economic Surveys 10 (1): 23-53.

Bureau of Labor Statistics (2018). Labor Force Statistics from the Current Population Survey - 47. Absences from work of employed full-time wage and salary workers by occupation and industry, https://www.bls.gov/cps/cpsaat47.htm (accessed 1 August, 2018).

Buurman, Margaretha, Josse Delfgaauw, Robert Dur and Seth Van den Bossche (2012). Public sector employees: Risk averse and altruistic? Journal of Economic Behavior \& Organization 83 (3): 279-291.

D'Amuri, Francesco (2017). Monitoring and disincentives in containing paid sick leave, Labour Economics 49: 74-83.

Darr, Wendy and Gary Johns (2008). Work Strain, Health, and Absenteeism: A Meta-Analysis, Journal of Occupational Health Psychology 13 (4): 293-318.

De Paola, Maria, Vincenzo Scoppa and Valeria Pupo (2014). Absenteeism in the Italian Public Sector: The Effects of Changes in Sick Leave Policy, Journal of Labor Economics 32 (2): 337-360.

Dionne, Georges and Benoit Dostie (2007). New evidence on the determinants of absenteeism using linked employer-employee data, Industrial and Labor Relations Review 61 (1): 108-120. 


\section{STEPHANIE PRÜMER/CLAUS SCHNABEL}

Dustmann, Christian and Arthur van Soest (1998). Public and private sector wages of male workers in Germany, European Economic Review 42 (8): 1417-1441.

Engström, Per and Bertil Holmlund (2007). Worker Absenteeism in Search Equilibrium, Scandinavian Journal of Economics 109 (3): 439-467.

Faragher, Jo (2016). Sickness absence rates remain stable, Personnel Today, 7 October 2016, http:// www.personneltoday.com/hr/sickness-absence-rates-remain-stable/ (accessed 20 October, 2017).

FOCUS Online (2017). Beamte sind doppelt so oft krank wie andere Arbeitnehmer - aber warum? http://www.focus.de/finanzen/news/krankenstand-schnellt-hoch-beamte-doppelt-so-oft-krankwie-arbeitnehmer-und-begruendung-ist-merkwuerdig_id_6590231.html (accessed 18 October, 2017).

Frick, Bernd and Miguel M. Malo (2008). Labor Market Institutions and Individual Absenteeism in the European Union: The Relative Importance of Sickness Benefit Systems and Employment Protection Legislation, Industrial and Labor Relations Review 47 (4): 505-529.

Gregory, Robert G. and Jeff Borland (1999). Recent Developments in Public Sector Labor Markets, in: Ashenfelter, Orley C. and David Card (eds.), Handbook of Labor Economics 3C. Amsterdam: North Holland: 3573-3630.

Hall, Anja, Anke Siefer and Michael Tiemann (2015). BIBB/BAuA Employment Survey of the Working Population on Qualification and Working Conditions in Germany 2012, suf_4.0, Research Data Center at BIBB (ed.), GESIS Cologne (data access). Federal Institute for Vocational Education and Training, Bonn. https://doi.org/10.7803/501.12.1.1.40

Johns, Gary (2009). Absenteeism or Presenteeism? Attendance Dynamics and Employee Well-Being, in: Cartwright, Susan and Cary L. Cooper (eds.), The Oxford Handbook of Organizational WellBeing. Oxford: Oxford University Press: 7-30.

Jung, Sven and Claus Schnabel (2011). Paying more than necessary? The wage cushion in Germany, Labour 25 (2): 182-197.

Knieps, Franz and Holger Pfaff (2016) (eds.). BKK Gesundheitsreport 2016. Berlin: Medizinisch Wissenschaftliche Verlagsgesellschaft.

Leigh, J. Paul (1991). Employee and job attributes as predictors of absenteeism in a national sample of workers: the importance of health and dangerous working conditions, Social Science \& Medicine 33 (2): $127-137$.

Livanos, Ilias and Alexandros Zangelidis (2013). Unemployment, Labor Market Flexibility, and Absenteeism: A Pan-European Study, Industrial Relations 52 (2): 492-515.

Lechmann, Daniel S.J. and Claus Schnabel (2014). Absence from work of the self-employed: A comparison with paid employees, Kyklos 67 (3): 368-390.

Long, J. Scott and Jeremy Freese (2006). Regression models for categorical dependent variables using Stata, $2^{\text {nd }}$ edition. College Station: Stata Press.

Lusinyan, Lusine and Leo Bonato (2007). Work Absence in Europe, IMF Staff Papers 54 (3): 475-538.

Maczulskij, Terhi (2017). Who becomes a public employee?, International Journal of Manpower 38 (4): $567-579$.

McGrandle, Jocelyn and Frank L.K. Ohemeng (2017). The conundrum of absenteeism in the Canadian public service: A wicked problem perspective, Canadian Public Administration 60 (2): $215-240$.

Meyer, Markus, Kristin Wehner and Patrick Cichon (2017). Krankheitsbedingte Fehlzeiten in der deutschen Wirtschaft im Jahr 2016, in: Badura, Bernhard, Antje Ducki, Helmut Schröder, Joachim Klose and Markus Meyer (eds.), Fehlzeitenreport 2017. Berlin: Springer: 281-484.

Kjeld Møller Pedersen, and Kristian Skagen (2014). The economics of presenteeism: a discrete choice \& count model framework, COHERE Working Paper No. 2014:2, Odense.

Oppolzer, Alfred (1999). Ausgewählte Bestimmungsfaktoren des Krankenstandes in der öffentlichen Verwaltung - Zum Einfluß von Arbeitszufriedenheit und Arbeitsbedingungen auf 
krankheitsbedingte Fehlzeiten, in: Badura, Bernhard, Martin Litsch, and Christian Vetter (eds.), Fehlzeiten-Report 1999. Berlin and Heidelberg: Springer: 343-362.

Osterkamp, Rigmar and Oliver Röhn (2007). Being on Sick Leave: Possible Explanations for Differences of Sick-leave Days Across Countries, CESifo Economic Studies 53 (1): 97-114.

Oto-Peralias, Daniel and Diego Romero-Ávila (2013). Tracing the Link between Government Size and Growth: The Role of Public Sector Quality, Kyklos 66 (2): 229-255.

Pfeifer, Christian (2010). Impact of wages and job levels on worker absenteeism, International Journal of Manpower 31 (1): 59-72.

Pfeifer, Christian (2011). Risk Aversion and Sorting into Public Sector Employment, German Economic Review 12 (1): 85-99.

Pfeifer, Christian (2013). Cyclical absenteeism among private sector, public sector and self-employed workers, Health Economics 22 (3): 366-370.

Riphahn, Regina T. (2004). Employment protection and effort among German employees, Economics Letters 85 (3): 353-357.

Riphahn, Regina T. and Anja Thalmaier (2001). Behavioral Effects of Probation Periods: An Analysis of Worker Absenteeism, Jahrbücher für Nationalökonomie und Statistik. 221 (2): 179-201.

Rohrbach-Schmidt, Daniela and Anja Hall (2013). BIBB/BAuA-Erwerbstätigenbefragung 2012, BIBB-FDZ Daten- und Methodenbericht 1/2013, Bonn.

Spierdijk, Laura, Gijsbert van Lomwel and Wilko Peppelman (2009). The determinants of sick leave durations of Dutch self-employed, Journal of Health Economics 28 (6): 1185-1196.

Steers, Richard M. and Susan R. Rhodes (1978). Major influences on employee attendance: A process model, Journal of Applied Psychology 63 (4): 391-407.

Störmer, Susi and René Fahr (2013). Individual determinants of work attendance: evidence on the role of personality, Applied Economics 45 (19): 2863-2875.

Thalmaier, Anja (2002). Eine ökonomische Analyse von Fehlzeiten. Frankfurt/Main: Lang.

Treble, John and Tim Barmby (2011). Worker Absenteeism and Sick Pay. Cambridge: Cambridge University Press.

Wooldridge, Jeffrey M. (2010). Econometric Analysis of Cross Section and Panel Data, 2nd edition. Cambridge (Mass.): MIT Press.

\section{SUPPORTING INFORMATION}

Additional Supporting Information may be found in the online version of this article at the publisher's website:

Appendix Table 1: Probit estimates of ever having been absent and truncated negative binomial estimates of number of absent days conditional on ever having been absent by sector affiliation (average partial effects), without considering health variables

Appendix Table 2: Probit estimates of ever having been absent and truncated negative binomial estimates of number of absent days conditional on ever having been absent by sector affiliation (average partial effects), only considering $\leq 50$ absent days 


\section{STEPHANIE PRÜMER/CLAUS SCHNABEL}

\section{SUMMARY}

Public sector employees are often said to have excessive rates of absence from work. Using representative survey data for Germany, we indeed find absenteeism of employees to be higher in the public than the private sector. The differences in the incidence and days of absence showing up in descriptive statistics are substantially reduced and partly disappear in our estimates of hurdle regression models controlling for individuals' socio-demographic characteristics, health status, professional activities, and for many workplace-related factors. Nevertheless, the probability of staying home sick at least once a year is still 5.6 percentage points higher in the public sector, ceteris paribus. This finding refutes popular assertions that differences in absence rates between the sectors are mainly due to structural factors like different compositions of the workforce. We show that the same observable factors play a role for absenteeism in the public and private sector, but we cannot rule out that shirking may play a more important role in the public sector. Nevertheless, we conclude that the stereotype of the "malingering bureaucrat" seems to be an exaggeration, at least for Germany. 